BRTISH MEDICAL JOURNAL VoLUME $287 \quad 17$ SEPTEMBER 1983 PRACTICE OBSERVED

Practice Research

\section{Does home monitoring of blood glucose work in general} practice?

R L GIBBINS, J SAUNDERS, C J ROWLANDS, J HARDING-DEMPSTER, A J M CAVENAGH

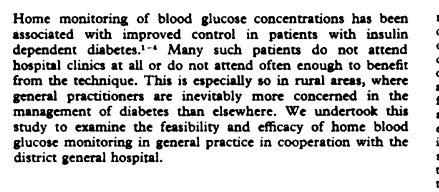

Method

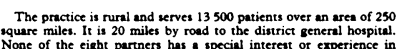

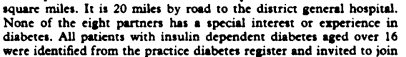

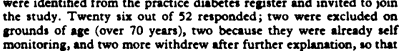

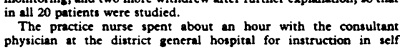

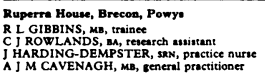

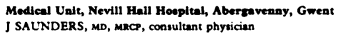

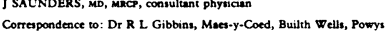
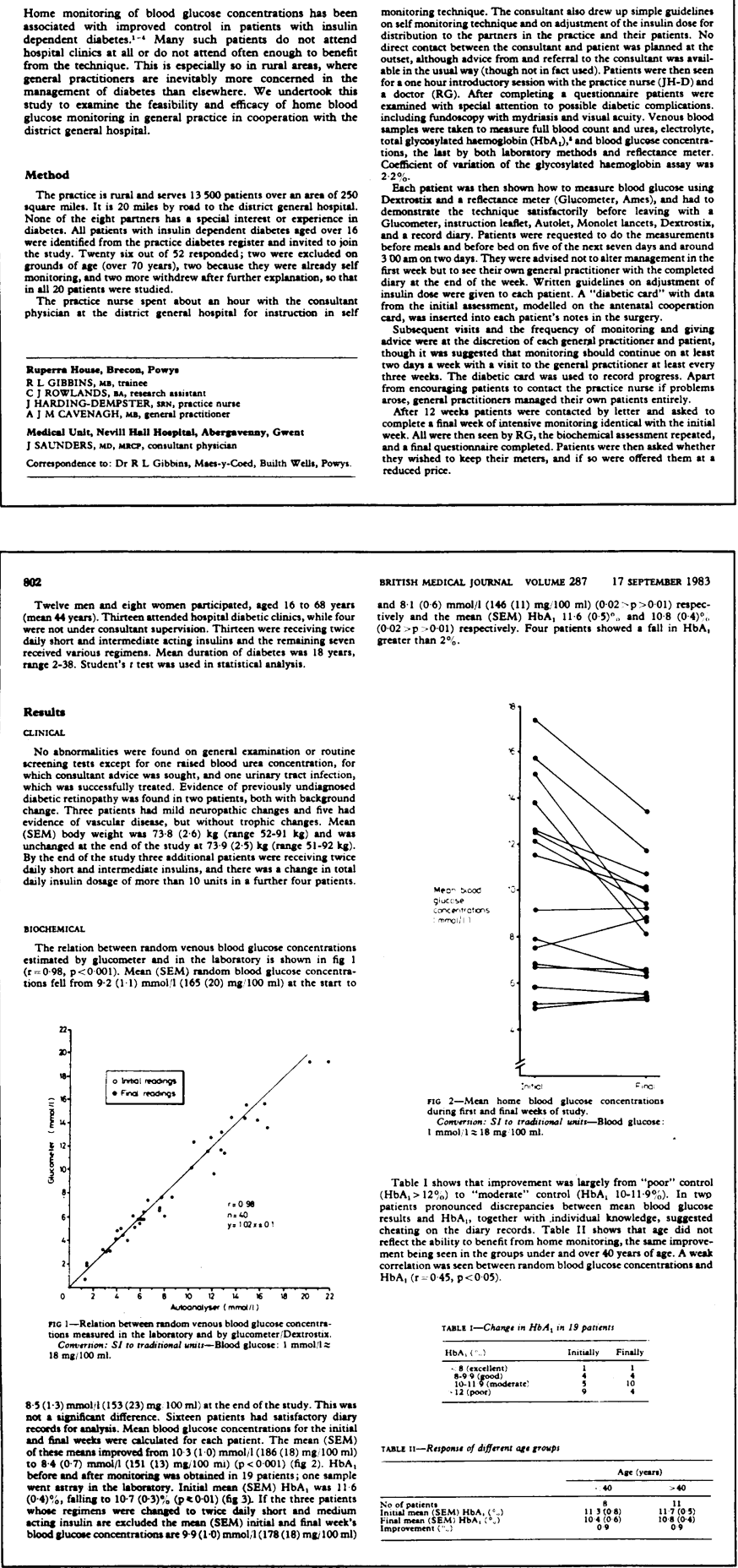
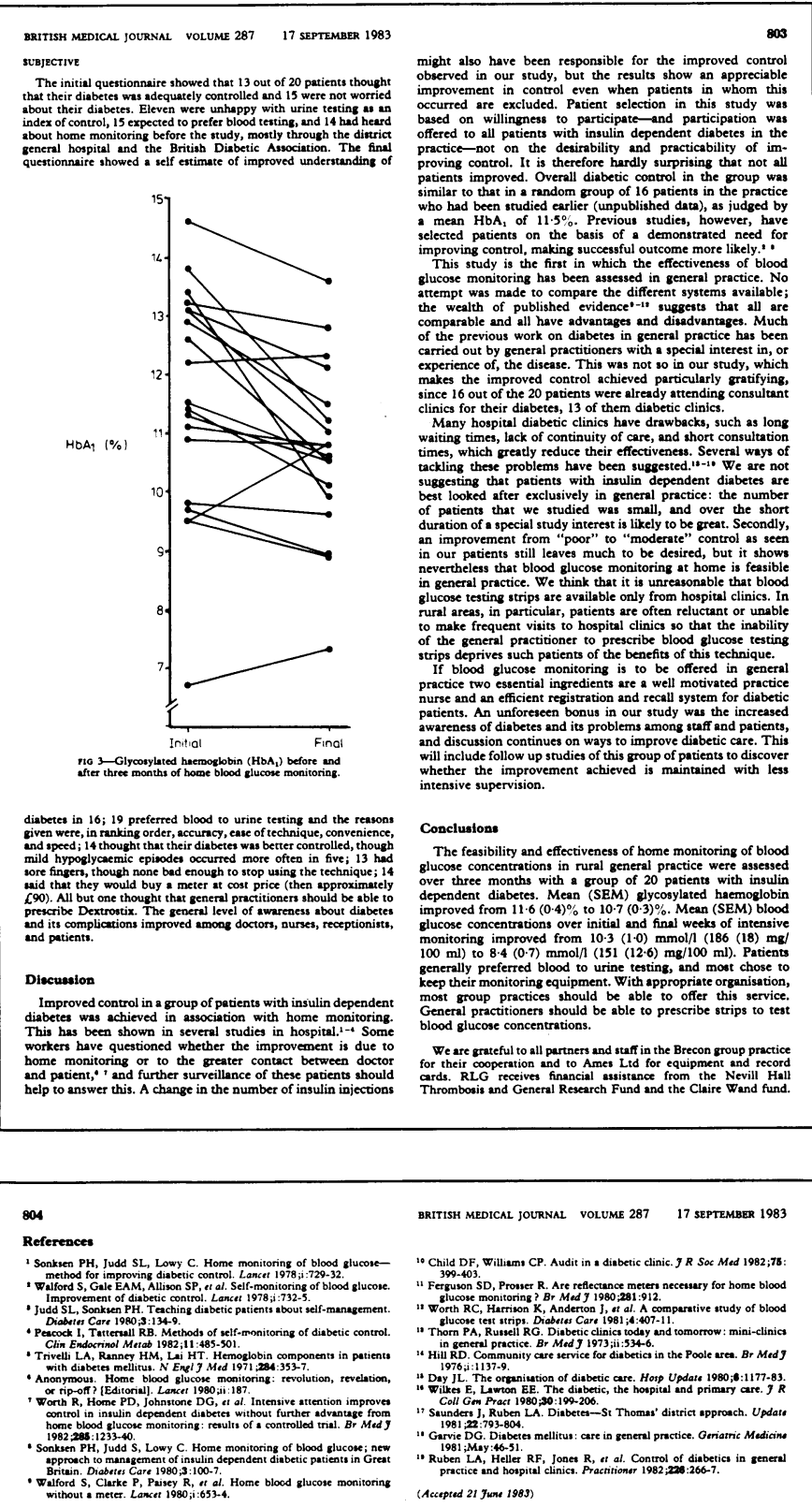

\section{Image of General Practice}

\section{Me and the general practitioners}

NICK ROss

I suffer from an allergy, and always have, to queucing. But you
need patience to be 2 patient.

Overcoming the laws

There's the Receptionists' Law to overcome to start with.
According to this canon, when you telephone for an appointment you have to wait while the receptionist copes with someone
queueneing before her at the surgery, and when you queve before queveing before her at the surgeryy and when you queve before
her at the surgery you have to wait while she copes with someSo you queuc to book, and on arrival you queuc to prove your
one presence before you queue to see the doctor. This all presumes
that the general practionen's time is morre precious than my
own, and I I suppose to him (or her) it is. But not to me. This Own, and I suppose to him 'or her') it is. But not to me. This
brings us to the second law, the Law of Physicks, which is
ingenous According to this. waiting for the doctor cuts down ingenious. According to this: waiting for the doctor cuts dow
waiting for the doctor. For queueuing deteres she likes of me fror seeking medical attention it reduces waiting times.
Then there's the Law of Medical Confidentiality. As the

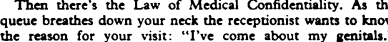

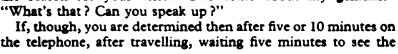

Lodon NWs

Correspondence to: 38 willes Rd, London NWS 3DL. 


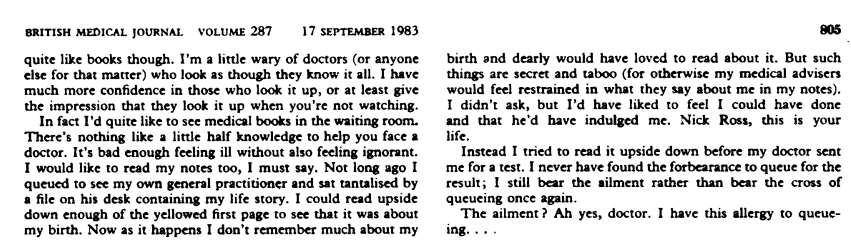

Papers That Have Changed My Practice

\section{Morbidity and prescribing}

T A CARNEY

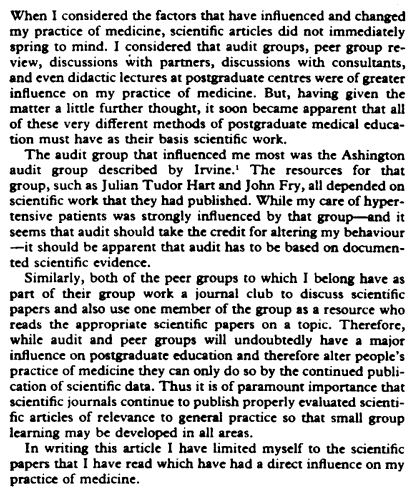

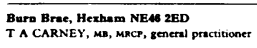

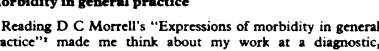

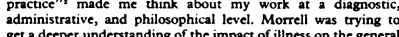

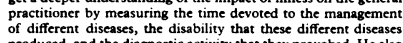

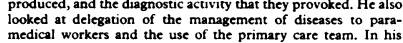

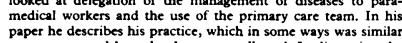

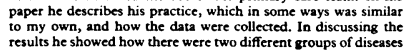

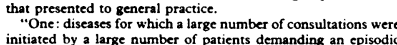

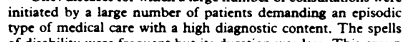

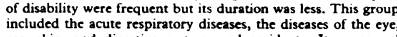
cart, skin, and digestive system, and accidents. It concerned "Two: disesess sor which a relatively small number of parients
consulted with a high frequency and many of these consultas tions being initiated by the doctor. The diagnosicic content of this

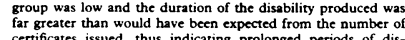

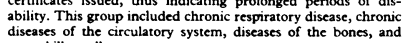

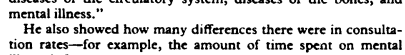

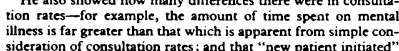

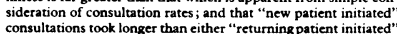

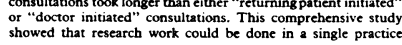

808

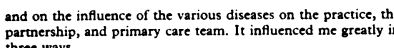

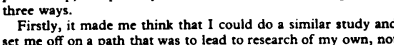

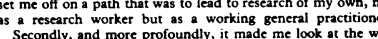

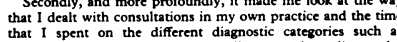

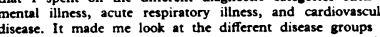

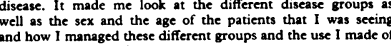

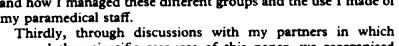

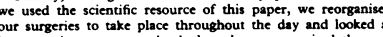

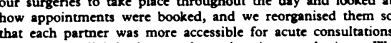

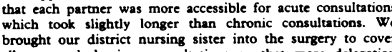

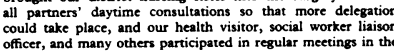

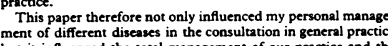

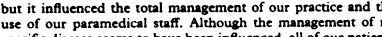

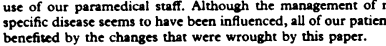

Diegrosit

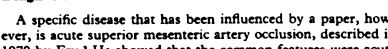

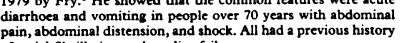

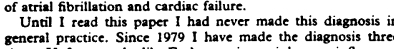

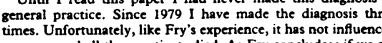

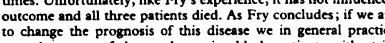

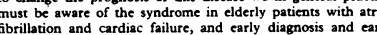

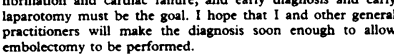

Clinical Judgment and antiblotice

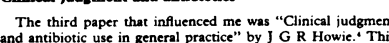

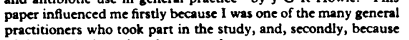

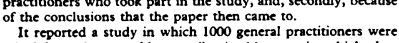

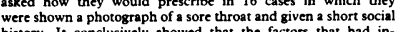

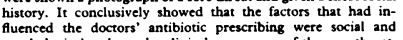

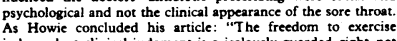

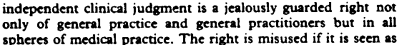

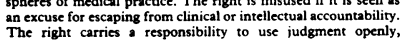

ocial and psychological implications and then take all three

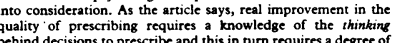
dissection and quantification of the components of clinical
judgment. This article made me think about my prescribing. laints of sore throat. Its implication was much wider. The process that this article started, and which I think was so important
a change in my practice of medicine in general practice, has
continued, and I will come back to it before the end of this
article.

\section{Behaviour of doctor}

On a lighter note the paper by P S Byrne and C C Heath on non-verbal behaviour by general practitioners in consultata-
tions, showining that those doctors who moved more during the
consultation had a better rapport with their patients, came as a reat relief to me. For many years, under the infuence of $m$ onal training organiser, $\mathrm{Dr} C \mathrm{C}$ Leon, I felt guilty about $m$ y nability to sit still during the consultation. I moved continuously used eye contact a great deal. For the first time this paper showed that by doing this perhaps my patients felt more an ease beceusse ted verbal communincacion chat it inplied.
By video taping real consultations in geral practice they patients and doctors. They also showed how silences and
reflected questions could only gain the best results if they were I doubt whether it greatly influenced my practice of medicine
but it most certainly made me feel a lot easier about the way in
which I did it.

\section{Prescribing}

Finally, what of the moment? What are the recent papers that
are influencing my habits now and makning mee change my
practice of medicine that will hopefully show up in years to practice of medicine that will hopefully show up in years to
come? ? There are four papers that continue the process started
by Howie and that are matis

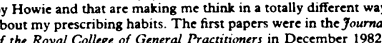
a the Royal College of General Practitioners in December 1982 .
a leader entitide "Stopping throid medication" by Kenneth
Mourin and the paper by Hopkins et al on "Benzodiazepine Mourin and the paper by Hopkins ef al on "Benzodiazepine drawing people from long term maintenance ereacment.
The first described how to check \& patient's thyroid statu required it. Having reviewed our patients on long term thyroid medication we know that most would meet modern criteria with
documented low thyroxine, and raised thyroid strimulating vere, is important if we are to audit and therefore diter our
prescing habits. prescrbing habits.
Similarly, the paper on benzodiazepine withdrawal showed
how one doctor purting one surgery a week to one side can use the how one doctor purting one surgery a week to one side can use the
present fieling of socicty in tist move away from drugs and can
remove well over $50^{\circ}$ of patients from long term use of the benzodiazepint
reported.
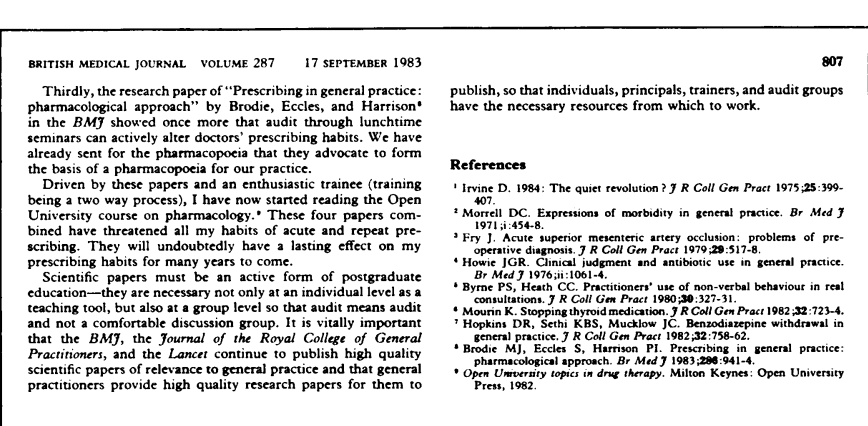

Diary of Urban Marks: 1880-1949

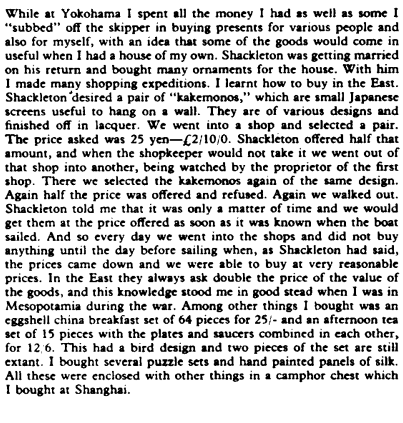

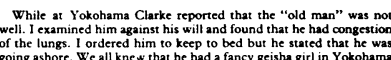

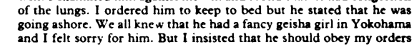

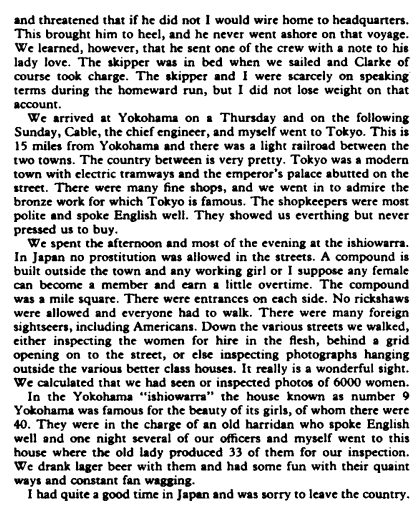

00

BRITISH MEDICAL JOURNAL VOLUME $287 \quad 17$ SEPTEMBER 1983

\section{New Idea} that shown that movement of the body and eye contact were at an inappropriate time.
I doubt whecher it greatly influenced my practice of medicine hormene assays, and our withdrawal rate has been much lower
han suggested. The concept of reviewing such patients, how-

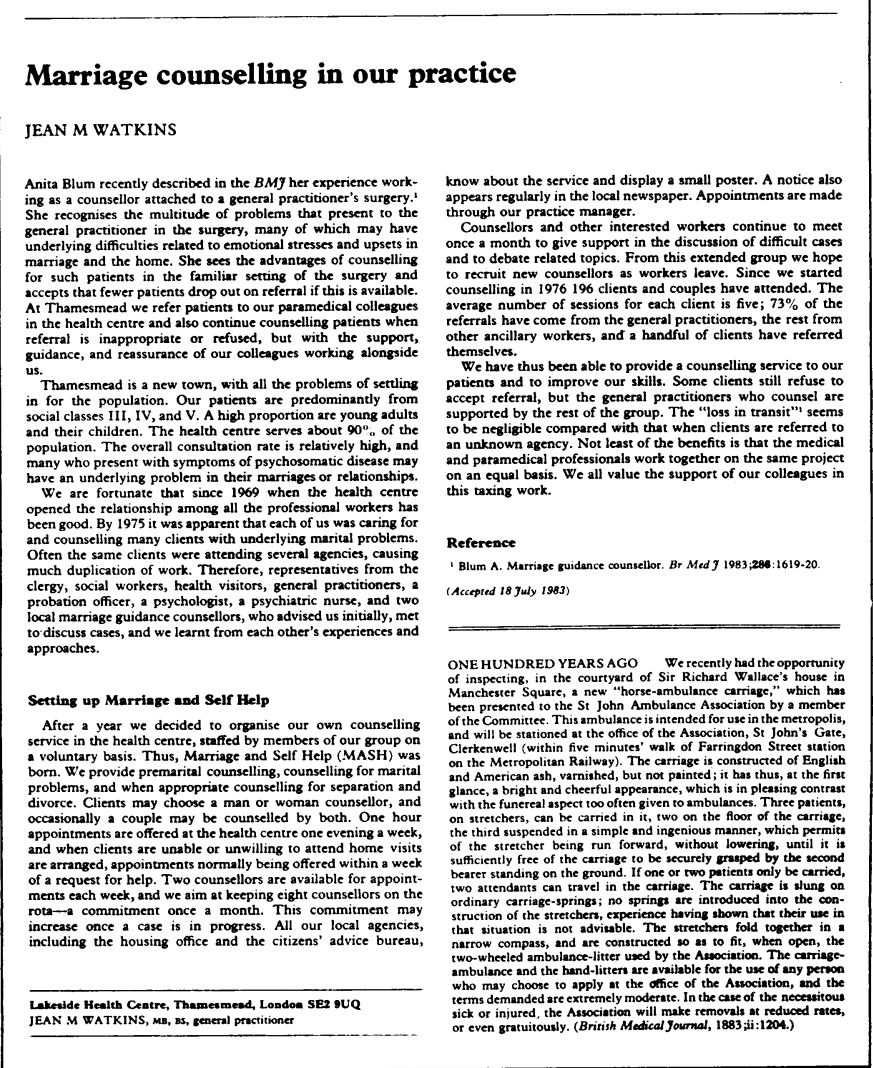

$\underline{\underline{m}}$

$\underset{\mathbb{1}}{3}$

$\widehat{c}$ 亏 ग्र m 